\title{
A Combined Cathodoluminescence and Wavelength Dispersive Spectrometry Study of Ti Zoning in Quartz from the Tuolumne Intrusive Suite in Yosemite, CA
}

\author{
Emma S. Bullock ${ }^{1}$ and Michael R. Ackerson ${ }^{1,2}$ \\ 1. Geophysical Laboratory, Carnegie Institution of Washington, 5251 Broad Branch Rd, N.W., \\ Washington, DC 20015. \\ 1,2. Rensselaer Polytechnic Institute, Troy, NY 12180
}

Quartz is an abundant mineral on Earth, and is a major component of groups of igneous, metamorphic and sedimentary rocks [e.g. 1]. Although quartz is predominately composed of $\mathrm{SiO}_{2}$, it can also host trace quantities of other elements such as Al, Ti, Fe, and Mn, which affect the colour of the mineral both under natural light (e.g., amethyst) and in terms of visible light emitted when the sample is targeted by a beam of electrons [e.g. 2]. Variations in trace element concentrations within individual quartz crystals can be used to determine the provenance and cooling history of individual grains and their host rocks. Here, we present a detailed study of Ti zoning in a series of low-temperature granitic rocks from California, utilizing electron probe microanalysis (EPMA) combined with the Ocean Optics xCLent cathodoluminescence (CL) spectrometer.

It is well-known that quartz emits luminescence when under an electron beam [e.g. 3]. The colour of the luminescence is dependent upon both intrinsic effects (such as lattice defects), and extrinsic effects (such as impurities). Different polymorphs (i.e. structural configurations) of $\mathrm{SiO}_{2}$ show CL emission at different wavelengths [e.g. Götze et al, 2001]. Quartz from the Tuolumne Intrusive Suite in Yosemite, California, typically has an emission spectra with a single peak at $\sim 650 \mathrm{~nm}$ wavelength. The addition of even trace quantities of titanium into the quartz lattice generates an emission within the blue region of the spectrum at $\sim 450 \mathrm{~nm}[4]$, the intensity of which is directly proportional to the amount of Ti in the quartz lattice. The amount of $\mathrm{Ti}$ that is soluble in the quartz lattice is a function of temperature, pressure and the chemical activity of $\mathrm{TiO}_{2}$ in the system as the quartz crystals grew, and thus can be used to infer information about the formation conditions of the host rock [5,6]. In the Tuolumne Intrusive Suite, the abundance of $\mathrm{Ti}$ in quartz is on the order of <50ppm: while it is possible to obtain high-precision chemical data of individual spots using an electron probe equipped with wavelength-dispersive spectrometers, high-resolution mapping of $\mathrm{Ti}$ zoning within quartz grains is not feasible at these low concentrations. Using a combination of CL and WDS mapping allows both precise compositional data to be obtained, along with zoning maps of high spatial resolution; if the accurate composition of a series of regions on the map is known, then these can be calibrated to produce a semi-quantitative map of $\mathrm{Ti}$ zoning across individual grains.

Quantitative chemical analyses were obtained using a JEOL 8530F field-emission electron probe at the Carnegie Institution for Science. The electron probe is equipped with five WDS detectors. Individual analyses were collected at $15 \mathrm{kV}, 200 \mathrm{nA}$, using a $10 \mu \mathrm{m}$ diameter electron beam, and utilizing the JEOL software. Peak count times were 300 seconds, and background counts were measured on either side of the peak for 150 seconds each. Ti k $\alpha$ was measured using the PET crystal on three different spectrometers, and the data combined. Because of the high count rate, the $2^{\text {nd }}$ order ka line of Si was measured. In addition, the k $\alpha$ line of $\mathrm{Al}$ was measured, as $\mathrm{Al}$ is a known impurity in quartz. Standards used were $\mathrm{TiO}_{2}$ (rutile), $\mathrm{Al}_{2} \mathrm{O}_{3}$, and $\mathrm{SiO}_{2}$. For CL mapping, the Ocean Optics xCLent IV spectrometer was used. This is a hyperspectral CL system that collects a full light spectrum per pixel, allowing for 
data to be interrogated after collection. CL maps were collected at $15 \mathrm{kV}, 20 \mathrm{nA}, 20 \mathrm{msec}$ dwell time, and $1 \mu \mathrm{m}$ per pixel. Maps of up to $2.5 \mathrm{~mm} \times 2.5 \mathrm{~mm}$ were collected, in order to sample full quartz grains. Since contact with the electron beam may result in structural changes within quartz that affect its intrinsic CL signal, care was taken to perform minimal imaging ahead of mapping.

The results of the CL mapping show that some quartz crystals grow concentrically, as might be expected for grains forming from a melt (Fig 1a), while other grains show a more unusual, sinuous zoning pattern (Fig 1b), most likely formed as a result of syn-magmatic deformation of the quartz. The Ti-poor regions of the quartz grains emit light primarily in the red region of the spectrum $(\sim 650 \mathrm{~nm})$, while the addition of Ti causes more intense emission in the blue wavelength $(\sim 450 \mathrm{~nm})$. Analyses of the Ti content of the quartz indicate crystallization at $\sim 474-561{ }^{\circ} \mathrm{C}$, which agrees with temperature range obtained using other mineral systems within the suite but is well below the temperature at which granites are traditionally thought to have formed [7]. Rim compositions generally record compositions of 20-40ppm Ti, lower than the $\sim 150-250 \mathrm{ppm}$ that might be expected at temperatures of $\sim 700^{\circ} \mathrm{C}$, the more typical temperature estimate for granite crystallization.

\section{References:}

[1] J. Götze, M. Plötze, and D. Habermann, Mineralogy and Petrology, 71 (2001) p225-250

[2] S Boggs Jr, Y-I Kwon, G. G. Goles, B. G. Rusk, D. Krinsley, A. Seyedoli, Journal of Sedimentary Research, 72 (2002) p408-415

[3] U. Zinkernagel, Contributions to Sedimentology, 8 (1978) p1-69

[4] W. P. Leeman, C. M. MacRae, N. C. Wilson, A. Torpy, C-T. A. Lee, J. J. Student, J. B. Thomas, E.

P. Vicenzi, Microscopy and Microanalysis, 18 (2012) p1322-1341

[5] J. B. Thomas, E. B. Watson, F. S. Spear, P. T. Shemella,, S. K. Nayak, A. Lanzirotti, Contributions to Mineralogy and Petrology (2010) 160 p743-759

[6] D. A. Wark and E. B. Watson, Contributions to Mineralogy and Petrology152 (2006) p743-754.

[7] M. R. Ackerson, B. O. Mysen, E. B. Watson, and N. D. Tailby, in review, Nature (2018)

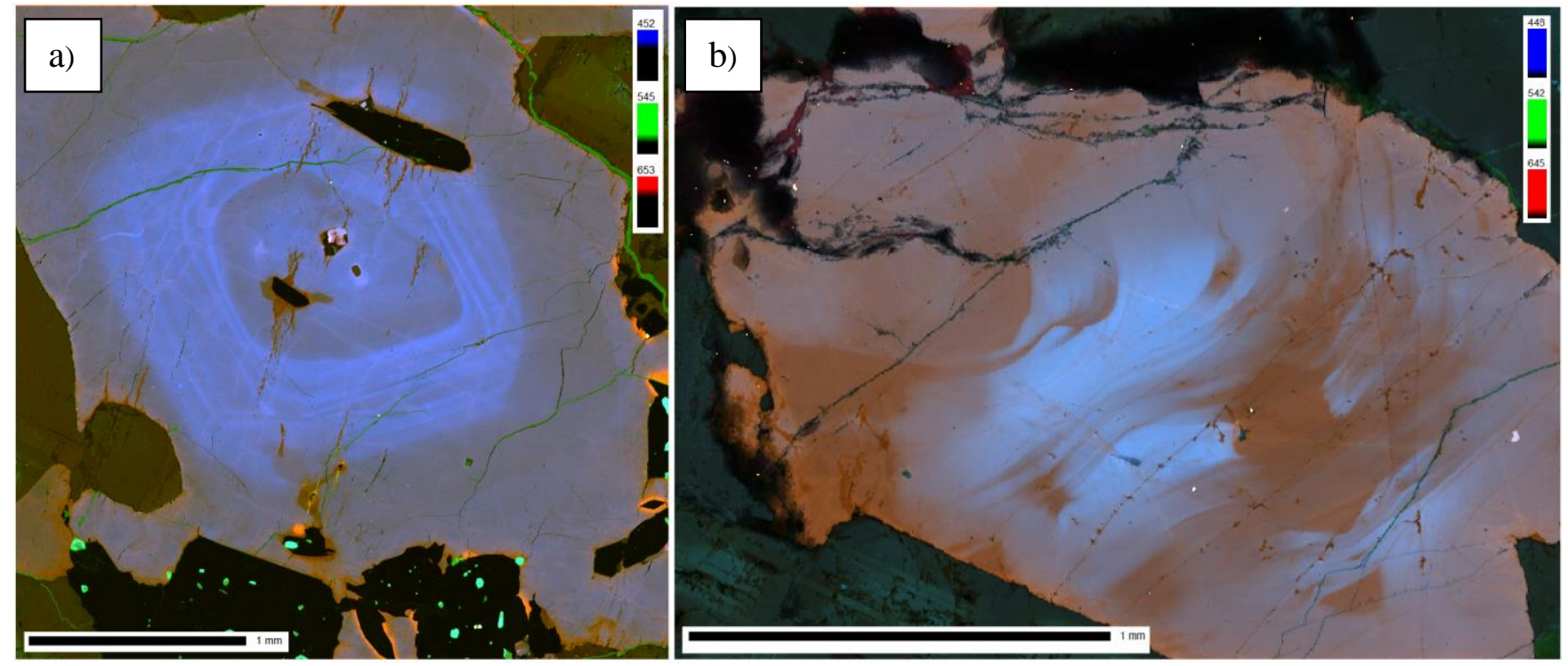

Figure 1. a) CL image of a quartz grain showing concentric zoning; b) Quartz grain exhibiting sinuous zoning pattern. The brighter blue regions have a higher Ti content. 